\title{
Topography and geomorphology of the Huygens landing site on Titan
}

\author{
Laurence A. Soderblom ${ }^{\mathrm{a}, *}$, Martin G. Tomasko ${ }^{\mathrm{b}}$, Brent A. Archinal ${ }^{\mathrm{a}}$, Tammy L. Becker ${ }^{\mathrm{a}}$, \\ Michael W. Bushroe ${ }^{\mathrm{b}}$, Debbie A. Cook ${ }^{\mathrm{a}}$, Lyn R. Doose ${ }^{\mathrm{b}}$, Donna M. Galuszka ${ }^{\mathrm{a}}$, \\ Trent M. Hare ${ }^{\mathrm{a}}$, Elpitha Howington-Kraus ${ }^{\mathrm{a}}$, Erich Karkoschka ${ }^{\mathrm{b}}$, Randolph L. Kirk ${ }^{\mathrm{a}}$, \\ Jonathan I. Lunine ${ }^{\mathrm{b}}$, Elisabeth A. McFarlane ${ }^{\mathrm{b}}$, Bonnie L. Redding ${ }^{\mathrm{a}}$, Bashar Rizk ${ }^{\mathrm{b}}$, \\ Mark R. Rosiek ${ }^{\mathrm{a}}$, Charles See ${ }^{\mathrm{b}}$, Peter H. Smith ${ }^{\mathrm{b}}$ \\ ${ }^{a}$ US Geological Survey, 2255 North Gemini Drive, Flagstaff, AZ 86001, USA \\ ${ }^{\mathrm{b}}$ Lunar and Planetary Laboratory, University of Arizona, Tucson, AZ, USA
}

Accepted 13 April 2007

Available online 27 April 2007

\begin{abstract}
The Descent Imager/Spectral Radiometer (DISR) aboard the Huygens Probe took several hundred visible-light images with its three cameras on approach to the surface of Titan. Several sets of stereo image pairs were collected during the descent. The digital terrain models constructed from those images show rugged topography, in places approaching the angle of repose, adjacent to flatter darker plains. Brighter regions north of the landing site display two styles of drainage patterns: (1) bright highlands with rough topography and deeply incised branching dendritic drainage networks (up to fourth order) with dark-floored valleys that are suggestive of erosion by methane rainfall and (2) short, stubby low-order drainages that follow linear fault patterns forming canyon-like features suggestive of methane spring-sapping. The topographic data show that the bright highland terrains are extremely rugged; slopes of order of $30^{\circ}$ appear common. These systems drain into adjacent relatively flat, dark lowland terrains. A stereo model for part of the dark plains region to the east of the landing site suggests surface scour across this plain flowing from west to east leaving $\sim 100$-m-high bright ridges. Tectonic patterns are evident in (1) controlling the rectilinear, low-order, stubby drainages and (2) the "coastline" at the highland-lowland boundary with numerous straight and angular margins. In addition to flow from the highlands drainages, the lowland area shows evidence for more prolific flow parallel to the highland-lowland boundary leaving bright outliers resembling terrestrial sandbars. This implies major west to east floods across the plains where the probe landed with flow parallel to the highland-lowland boundary; the primary source of these flows is evidently not the dendritic channels in the bright highlands to the north.
\end{abstract}

(C) 2007 Elsevier Ltd. All rights reserved.

Keywords: Titan; Huygens Probe; DISR; Topography; Stereogrammetry; Methane; Drainage; Fluvial; Dendritic; Tectonic

\section{Introduction}

The Descent Imager/Spectral Radiometer (DISR) carried aboard the Huygens Probe (Tomasko et al., 2002) acquired 1134 visible-light images with its three cameras during descent to and following landing on Titan's surface (Tomasko et al., 2005). These cameras returned the first ever high-resolution $(\sim 60 \mathrm{~m} /$ pixel to a few $\mathrm{mm} /$ pixel $)$ images of the surface. About half of these images were lost due to the failure to receive the Channel A data from

\footnotetext{
*Corresponding author. Tel.: + 19285567018 ; fax: + 19285567014

E-mail address: 1soderblom@usgs.gov (L.A. Soderblom).
}

the Huygens Probe at the Cassini Orbiter (Tomasko et al., 2005 ) but 580 were successfully returned to Earth. Of these, 223 images were returned from the surface after landing. Of the remaining returned descent images, 240 were acquired below $40 \mathrm{~km}$ at about the altitude where surface detail began to emerge through Titan's thick, scattering aerosol haze. While much of the stereo coverage was lost with the Channel A data, the image set does provide extensive coverage of the region around the Huygens landing site. The analysis of some of the remaining stereo coverage is the main subject of this paper.

The three DISR visible-light cameras include: the highresolution imager (HRI), the medium-resolution imager 


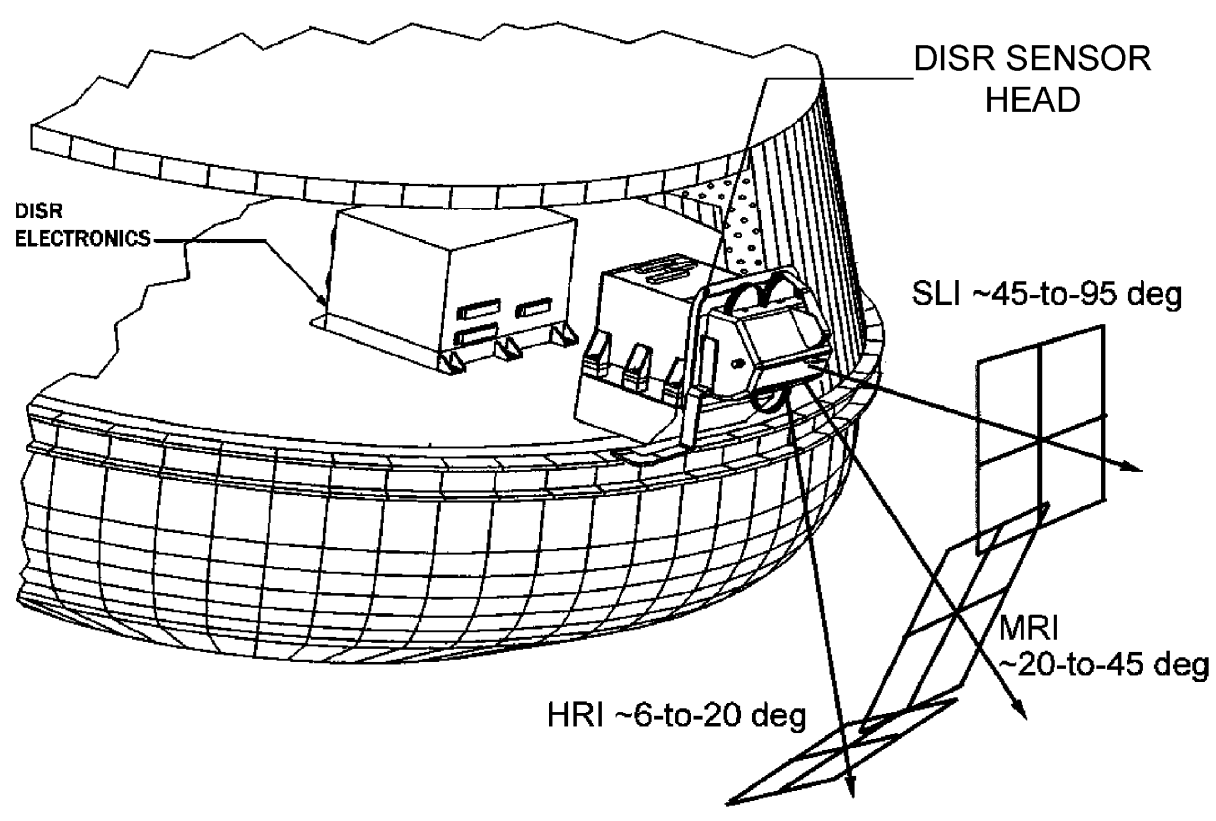

Fig. 1. Schematic layout of the fields-of-view (FOVs) of the DISR visible-light cameras. Angles denote approximate positions of the tops and bottoms of the FOVs from nadir. See Table 1 for further detail.

Table 1

Summary characteristics of the DISR camera

\begin{tabular}{lllcc}
\hline Camera & Format, pixels & Pixel (deg.) & Range from Nadir (deg.) & Azimuth range (deg.) \\
\hline Side-looking imager-SLI & $128 \times 256$ & 0.20 & $45.2-96.0$ & 25.6 \\
Medium resolution imager-MRI & $176 \times 256$ & 0.12 & $15.75-46.25$ & 21.1 \\
High resolution imager-HRI & $160 \times 256$ & 0.06 & $6.5-21.5$ & 9.6 \\
\hline
\end{tabular}

(MRI), and side looking imager (SLI); Fig. 1 shows the general layout and Table 1 provides basic geometric properties of the cameras. During imaging sequences all three cameras were exposed simultaneously providing a strip of image coverage from just off of nadir to $j$ ust above the horizon. As the probe spun and drifted laterally during descent, panoramas were built up in cartwheel patterns.

\section{Stereo coverage}

The descent plan called for useful stereo coverage to be collected only with the HRI and MRI cameras; the surface resolution and emission angles from the SLI would not be appropriate for this application. For lateral view directions (i.e. perpendicular to the drift direction) HRI-HRI and MRI-MRI provide stereo; for the fore and aft directions HRI-MRI pairs can also be used. The DISR imaging sequence was designed to acquire stereo coverage assuming substantial eastward drift of the probe during descent driven by the prograde zonal wind. It was thought that the surface could become visible between 50 and $90 \mathrm{~km}$ and the wind drift would be $10-50 \mathrm{~m} / \mathrm{s}$. Thus it was anticipated that the imaging coverage might be spread out eastward several hundred $\mathrm{km}$.
During the actual descent two major factors affected the stereo coverage: (1) the troposphere was hazier than anticipated so that the surface was not adequately resolved to accurately measure photogrammetric positions until reaching $\sim 20 \mathrm{~km}$ altitude and (2) by that altitude the wind speed had dropped to $\sim 4 \mathrm{~m} / \mathrm{s}$, continued to decrease with altitude, and actually reversed below $\sim 7 \mathrm{~km}$ drifting back to the northwest at $\sim 1 \mathrm{~m} / \mathrm{s}$ (Tomasko et al., 2005). As a result, in the last $20 \mathrm{~km}$ the descent was almost straight down with little lateral drift. Fig. 2 shows the geometry of the descent below $20 \mathrm{~km}$ where photogrammetrically usable stereo image data were acquired for the two regions in region of the Huygens landing site (HLS) for which digital terrain models (DTMs) were generated in this work. Table 2 provides current best estimates (Karkoschka, 2006) of the camera positions for the seven DISR images of the stereo pairs depicted in Fig. 2. Fig. 3 shows the larger region of the full DISR image coverage.

Because of the rapid decrease in lateral drift rate below $20 \mathrm{~km}$, DISR returned a series of panoramas mostly of the same region but each with increasingly higher resolution than the last. This was fortunate for several reasons: (1) owing to the loss of the Channel A data each panorama was partial and repeated coverage ultimately provided useful images of the entire landing site region, (2) having 


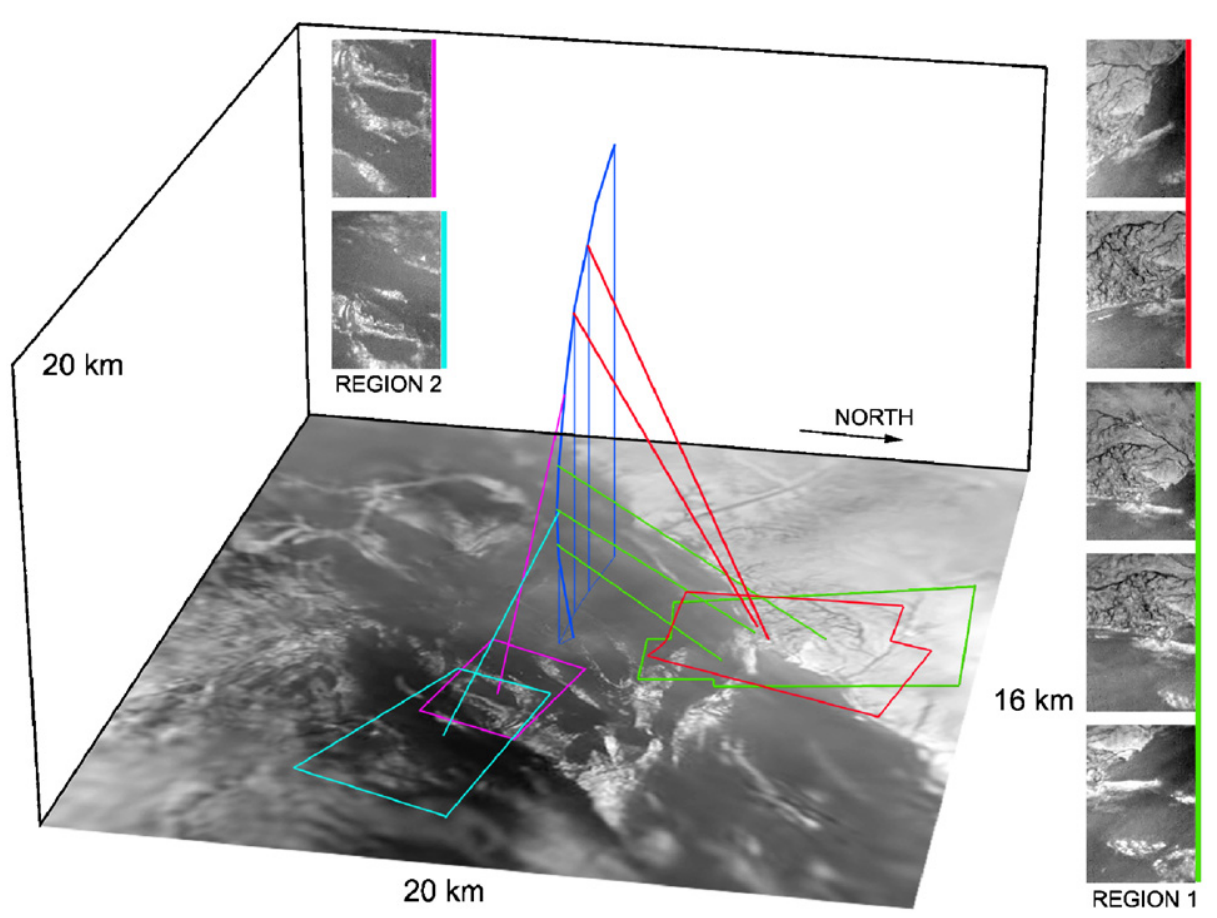

Fig. 2. West-looking perspective view showing the location and geometry of the DISR stereo images described here. Also shown is the Huygens descent trajectory (in blue, vertical blue lines denote ground track location). The Huygens landing site (current best estimate $10.4^{\circ} \mathrm{S}, 192.4^{\circ} \mathrm{W}$ ) is at the center of the view. Region 1 images (on right, top down) are HRI 414, HRI 450, MRI 553, MRI 601, MRI 634. Region 2 images (on left top down) are HRI 498 and MRI 595. Camera stations for the stereo images are provided in Table 2. The base map is $16 \mathrm{~m} /$ pixel DISR mosaic from Karkoschka (2006).

Table 2

Huygens Probe positions relative to landing site for stereo image sets shown in Fig. 2

\begin{tabular}{lllllr}
\hline Region & Image ID & Camera & $\begin{array}{l}\text { Altitude } \\
(\mathrm{km})\end{array}$ & $\begin{array}{l}\text { North } \Delta \\
(\mathrm{km})\end{array}$ & $\begin{array}{l}\text { East } \Delta \\
(\mathrm{km})\end{array}$ \\
\hline 1 & 414 & HRI & 16.61 & -0.13 & -1.96 \\
1 & 450 & HRI & 14.44 & -0.18 & -0.95 \\
1 & 553 & MRI & 8.71 & -0.19 & 0.62 \\
1 & 601 & MRI & 6.60 & -0.19 & 0.73 \\
1 & 634 & MRI & 5.07 & -0.16 & 0.68 \\
2 & 498 & HRI & 11.89 & -0.19 & -0.02 \\
2 & 595 & MRI & 6.78 & -0.19 & 0.73 \\
\hline
\end{tabular}

images for context at higher altitudes for the lower altitude higher resolution (often isolated) frames certainly aided in the interpretability of the surface processes, and (3) repeated coverage yielded a number of same-side, highlow, HRI-MRI pairs with adequate parallax to measure surface topography (Fig. 2). For these stereo pairs the HRI images were acquired from roughly twice the altitude as were the MRI images. Combined with the factor of two difference in angular resolution between the two cameras, images in these pairs have roughly the same resolution further facilitating the stereogrammetric analysis.

\section{Digital terrain models}

A digital photogrammetric workstation, running commercial software (SOCET SET ${ }^{\mathbb{R}}$ BAE) that was adapted for planetary mapping was used to derive DTMs from the overlapping pairs of DISR images. The workstation is first used to photogrammetrically adjust the images relative to each other and to solve for relative camera orientations and probe positions. Once the relative adjustment is performed, it is usually possible to use automatic matching techniques to derive DTM information. However, due to noise and compression artifacts in the images and their small size, attempts to use automated matching were not successful and the DTM information (for individual "posts") was tediously edited or collected manually. For each stereo model, in addition to a DTM, a pair of orthorectified images was also generated. The best of these were merged into an orthophoto mosaic that was color-coded and rendered into 3-D for the portrayals in Figs. 4-7. Table 3 provides geometric parameters for the centers of the overlap areas for the stereo pairs analyzed for the two regions shown in Fig. 2. The final topographic models for the two regions described here (DTMs and orthorectified images) are available at http://webgis.wr.usgs.gov/pigwad/ down/titan_dl.htm.

\subsection{Region 1 DTM}

Fortuitously, the most robust set of images with which to construct a DTM consists of six overlapping stereo pairs (utilizing 2 HRI and 3 MRI images, Table 3) that straddle the major bright-dark boundary between the bright rugged highlands with dark dendritic drainages $5 \mathrm{~km}$ north of the HLS and the lower plains where Huygens landed that 
exhibit evidence of fluvial scour (Tomasko et al., 2005). Fig. 4 shows perspective views (with no vertical exaggeration and simulated emission angles of $45^{\circ}$ ) and Fig. 5 provides a quantitative scale for the digital elevations. The area of the region is roughly $3 \times 5 \mathrm{~km}$. The integrated DTM was then arbitrarily leveled (residual tilt reduced); this was necessary as no surface datum yet exists. Noteworthy is the ruggedness of the topography; in many places the slopes are near $30^{\circ}$, or about the angle of repose for most unconsolidated natural materials. The white dots in Fig. 5 show the location of what we interpret to be a drainage divide that is discussed later in this paper.

\subsection{Region 1 error analysis}

Because the Region 1 DTM was constructed by pairing each of 2 HRI images with each of 3 MRI images, yielding six overlapping stereo pairs, it is possible to do error analyses by comparing models (Archinal et al., 2006). In addition results by separate human operators were compared. In initial evaluation of the DTMs, questions arose about the validity of a depression near the top of the DTM as seen in Fig. 5. This appears as a shallow bluish basin (top right side of Fig. 5) that is bounded on the south by a ridge along the north edge of the most prominent drainage in the image. Stereo pairs HRI 414/MRI 601 and HRI 414/MRI 553 cover this part of the DTM that is in question. Separate operators have verified that a depression is evident in HRI 414/MRI 601. The pair HRI 414/ MRI 553 does not show the depression, probably because MRI 553 has the lowest-resolution and poorest quality image in the set. To assess the overall DTM quality, three operators independently extracted DTMs from each of the

Table 3

Geometric image parameters at the center-of-overlap for the stereo pairs used in this study.

\begin{tabular}{llllll}
\hline $\begin{array}{c}\text { Region HRI } \\
\text { image }\end{array}$ & $\begin{array}{l}\text { MRI } \\
\text { image }\end{array}$ & $\begin{array}{l}\text { Convergence } \\
\text { angle }\end{array}$ & $\begin{array}{l}\text { HRI res. (m/ } \\
\text { pix })\end{array}$ & $\begin{array}{l}\text { MRI res. (m/ } \\
\text { pix })\end{array}$ \\
\hline 1 & 414 & 553 & 12.1 & 18.1 & 20.8 \\
1 & 414 & 601 & 16.1 & 17.9 & 16.3 \\
1 & 414 & 634 & 18.7 & 17.9 & 13.0 \\
1 & 450 & 553 & 9.5 & 15.8 & 20.7 \\
1 & 450 & 601 & 13.8 & 15.6 & 16.2 \\
1 & 450 & 634 & 16.7 & 15.6 & 12.9 \\
2 & 498 & 595 & 5.3 & 13.1 & 15.7 \\
\hline
\end{tabular}

six overlapping stereo pairs. Comparisons were then made using the SOCET SET quality statistics tool; results are shown in Table 4. First, comparison of overlapping DTMs extracted by the same operator gives an understanding of how well the images are photogrammetrically bundle adjusted. Second, operator-to-operator comparisons give an understanding of the expected precision of the data. Third, we compared the averaged error estimates with those weighted by stereo pair quality and resolution. Because MRI 553 is of significantly lower resolution than the other images in this set, error statistics were computed with and without the influence of this image. As expected, most of the error is attributable to input data quality, rather than operator (all operators had more than 10 years of experience). In conclusion, this DTM is estimated to have an accuracy of $\sim 30 \mathrm{~m}$ in surface elevation; there is, however, insufficient redundant data to verify the questionable depression.

\subsection{Region 2 DTM}

The second stereoscopically mapped area (Region 2) consists of only a single HR-MRI stereo pair but covers an area in the dark plains region where bright ridges stand out and in places appear to divert surface flow (Figs. 6 and 7). The errors in this model are somewhat higher than for Region 1 (probably $30-50 \mathrm{~m}$ ) owing to the low convergence angle in the area of image overlap (Table 3) and the lack of redundant images. Nonetheless this is an important data set as it is the only stereoscopic data available for the dark plains upon which the Huygens Probe landed. Even with the larger error in this topographic model it is clear that the bright strands of material that lace through the dark plain have positive relief and are ridges that are $\sim 100 \mathrm{~m}$ in height.

\section{Regional context: comparison with RADAR and VIMS data}

The Cassini RADAR synthetic aperture radar images (SAR) show RADAR-dark longitudinal dunes forming vast "sand seas" throughout Titan's optically dark equatorial regions (Lorenz et al., 2006b). In order for saltation to occur to form the dunes these workers conclude that the dune material must be relatively coarse grained $(100-300 \mu \mathrm{m})$. Through correlation of DISR SLI (in which the surface is visible $>50 \mathrm{~km}$ from the Huygens

Table 4

Error estimates for Region 1 based on comparisons between individual stereo models and operators

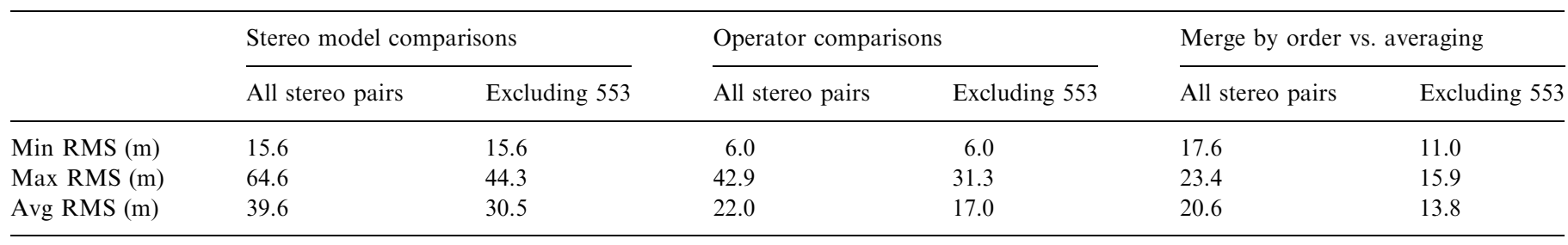


landing site) with SAR images, Lunine et al. (submitted) show the nearest dunes to be about $30 \mathrm{~km}$ north of the HLS (also see Fig. 3) and the immediate region of the landing site (e.g. the area covered in the mosaic base in Fig. 2) is largely dune-free. Other than these few dunes there is remarkably little correlation between features seen in the SAR images and in DISR; possible reasons are summarized next.

A number of studies have shown that short-wavelength infrared $(1-2 \mu \mathrm{m})$ spectral properties of optically dark regions are consistent with dirty water ice whereas the bright regions are consistent with lower concentrations of water ice (Coustenis et al., 1995, 2005; Griffith et al., 2003; McCord et al., 2006; de Pater et al., 2006; Negrão et al., 2006, 2007; Hirtzig et al., 2007). Soderblom et al. (this issue) show that based on Cassini VIMS spectra (Visible and Infrared Mapping Spectrometer) the dark units can be further subdivided into two groups: one of which appears enriched in water ice and a second dark unit that appears relatively water-ice poor. Barnes et al. (2007) also recognize these two dark units. Soderblom et al. (this issue) show that the water-ice-poor dark units correlate strongly, if not uniquely, with the vast dunes seen in Cassini RADAR images. They hypothesize that the dunes are composed of coarse hydrocarbon and/or nitrile grains mixed with lesser amounts of water ice. They advance a simple model in which Titan's surface units consist of a dirty water-ice optically dark substrate that is mantled by two types of hydrocarbon- and/or nitrile-rich deposits: fine bright aerosol dust and dark coarse grains of the dunes. Soderblom et al. suggest further that the mantles of bright aerosol material are effectively transparent in RADAR SAR images leading to the lack of correlation between

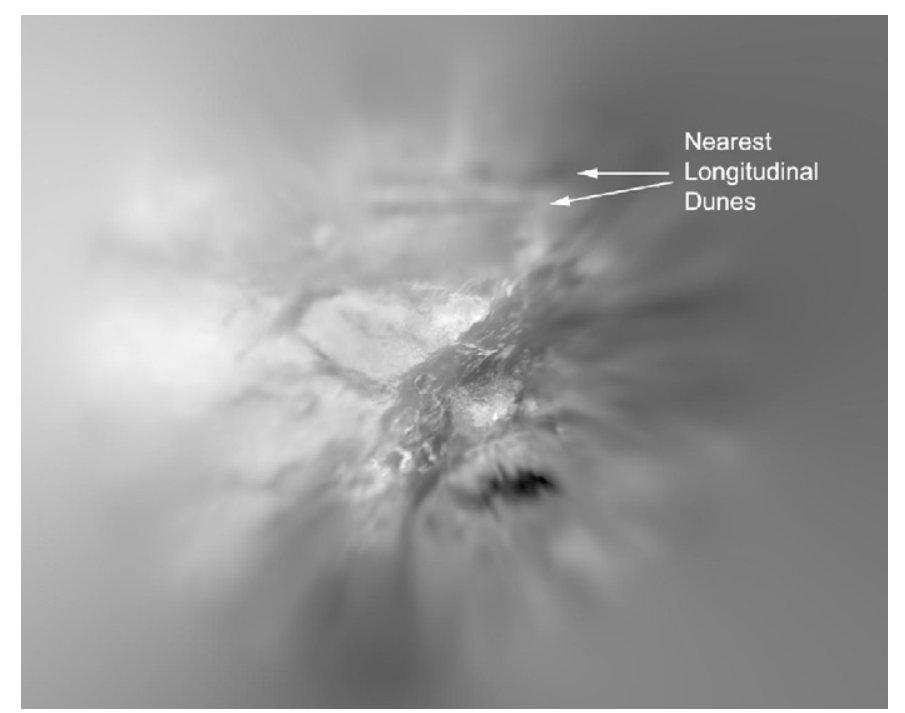

Fig. 3. Complete region of DISR image surface coverage (mosaic from Karkoschka, 2006). The mosaic covers an area of $128 \times 160 \mathrm{~km}$. SLI image coverage extends out well beyond the nearest dark dunes $\sim 30 \mathrm{~km}$ to the north also seen in the Cassini RADAR SAR images (Lunine et al., submitted). The region shown covers approximately $9.0-11.8^{\circ} \mathrm{S}$, $190.6-194.2^{\circ} \mathrm{W}$; the map projection is simple cylindrical.
DISR and RADAR at higher resolution or between VIMS and RADAR on the regional scale. VIMS data show that Huygens landed in region where both the dark water-ice enriched substrate and the bright material, evidently lower in water ice, are exposed. This is consistent with results of Rodriguez et al. (2006) in analysis of VIMS spectra and with the results of the DISR near-IR spectra $(0.87-1.7 \mu \mathrm{m})$ that show evidence of water ice in the dark plain of the landing site (Tomasko et al., 2005).

\section{Geomorphology: discussion and interpretation}

Tomasko et al. (2005) interpret the dark channel networks seen in the bright highlands to be carved by flow of liquid methane or methane-ethane liquid, generated either by rainfall or by springs or both. Collins (2005) shows that despite enormous differences in environment, fluvial erosion rates by water on Earth and methane on Titan are likely to be quite similar for similar stream channels. The drainages seen in the 3-D models (cf. Fig. 5) are dark by about a factor of two compared to the adjacent bright material. Consistent with Tomasko et al. (2005) we interpret this due to lower albedo material on the floors of the channels. Alternatively, Grieger et al. (2006) suggest that the dark floors could be entirely an effect of shading. They argue that the strong directional component of the solar aureole (solar incidence $\sim 35^{\circ}$, solar azimuth $\sim 125^{\circ}$ ) in the diffuse illumination of the surface would be adequate to introduce such topographic shading. Although some weak shading is expected, we do not find it compelling that this is a significant effect for several reasons: Valleys aligned toward the Sun should exhibit reduced shading compared to those oriented at $90^{\circ}$ which is not observed. Second, the brightness variations appear strongly bimodal as would be expected for an albedo contrast between two uniform materials rather than for continuously varying shading. Third, for shading to produce the very dark valley floors would seem to require an unnatural rapid increase slope (downward) just at the base of the adjacent bright slopes. Fourth some of the channels exhibit enlarged sections (Fig. 5) along their lengths and at junctions, perhaps where the flow was ponded, which would be difficult to understand in a shading-only model. Finally, cobbles at the landing site exhibit only weak shading. We conclude that the bright highlands and incised dark-floored valleys (cf. Region 1) represent materials with distinctly different albedos that are $\sim 0.1$ and $\sim 0.2$ (in the visible spectral region of the DISR cameras, centered $\sim 0.7 \mu \mathrm{m}$ ).

There are two distinctively different styles of drainage network in the bright highlands. Both show elements of tectonic control to varying degrees as does the "coastline" between the bright and dark regions, characterized in places by sharp, angular junctions between linear segments. The first type of drainage is an intermediate-order integrated dendritic network mapped in Region 1 (Figs. 4 and 5). Perron et al. (2006) provide an excellent discussion of these networks and comparisons with analogous 
terrestrial systems. This style is prevalent in the right-hand side of the upper panel in Fig. 8. These branching networks are at least fourth order (number of tributary branches counted upstream from the boundary with the dark plains). In terrestrial systems such dendritic systems are the result of a distributed source, that is, rainfall. In the case of Titan the rainfall is presumed to be precipitating methane or a methane-ethane mixture (in which, by virtue of the vapor pressures, methane dominates). Another interesting char-

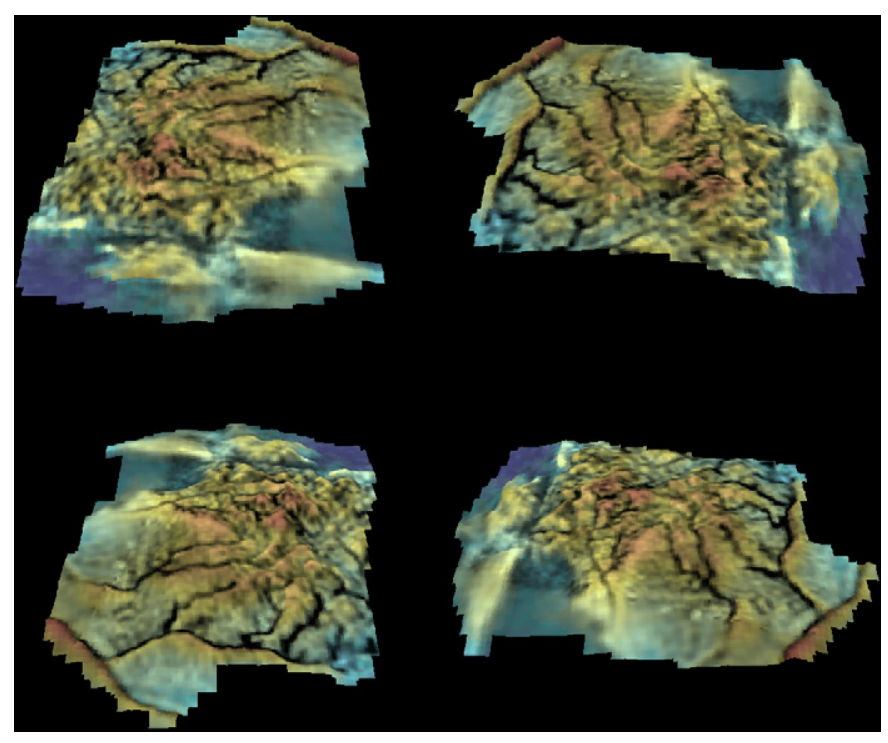

Fig. 4. Four perspective views of the composite DTM derived from six stereo models for Region 1 (upper left: N-looking, upper right: E-looking, lower left: S-looking, lower right: W-looking). The HRI and MRI images were orthorectified, mosaicked, color-coded in elevation (blue-to-red $\sim 250 \mathrm{~m}$ ) and then rendered into these 3-D views. There is no vertical exaggeration. acter of these networks is that the DTM suggests a topographic divide that separates two sets of drainages: one that flows north and eastward and another south and eastward (seen in stereo in Fig. 5). In places the divide has been breached and drainages have evidently begun capturing one another.

By contrast the drainage system in the left side of the same panel (Fig. 8 upper) shows a very different pattern. This style exhibits much lower order branching (only second and third order) with short "stubby" upper tributaries (Tomasko et al., 2005). Rather than rainfall this is more characteristic of spring sapping at the heads of closed canyons seen in many arid parts of the Earth (for example in the southwestern United States). Although the eastern drainages (Region 1) exhibit several linear segments suggestive of tectonic influence, the lower-order style on the west side of the panel appears much more strongly tectonically controlled, evidently by linear fault patterns; these are delineated in Fig. 9. We further speculate that a bright deposit of material may have been extruded into and onto this canyon system; in places this bright unit forms linear patterns as if it were confined by fault valley walls. Perhaps this represents an eruption of fresh material (i.e. cleaner) from ammonia-water cryovolcanism, a process believed to be likely operative at Titan's surface (Lewis, 1971, Stevenson, 1992; Lopes et al., 2007). In this interpretation the faults were later reactivated, forming zones of weakness for the methane fluid to erode the nowdark channel floors.

The lower left panel in Fig. 8 illustrates the erosive flow across the dark plains unit that surrounds the Huygens landing site. Flow here is generally from WNW to ESE and appears to be down-cutting from one plains level to another. DISR images acquired of the surface after landing

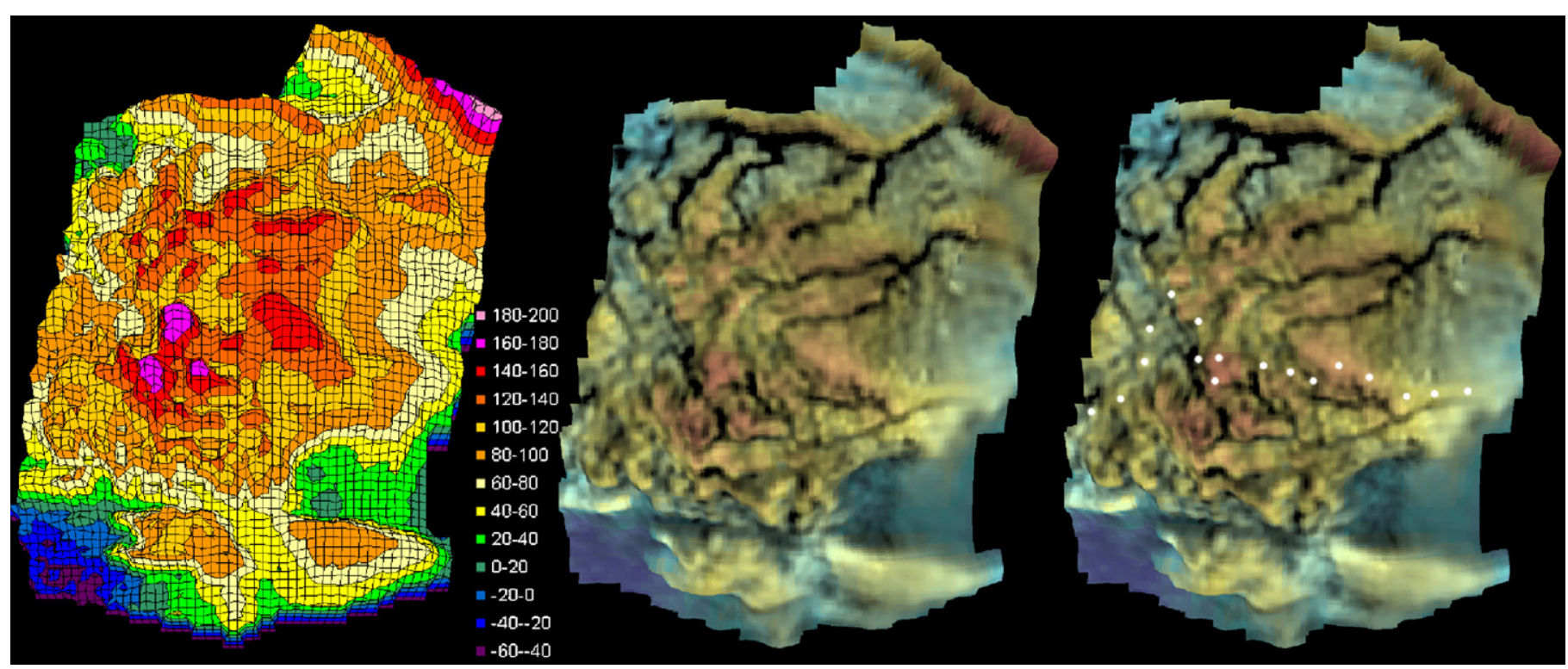

Fig. 5. Vertical views of the DTM for Region 1. Left: elevations are color-sliced and provided with a scale (units are in meters; grid spacing is $50 \mathrm{~m}$ ). Right pair: the elevation-color-coded orthorectified mosaic used in Fig. 4 is rendered here into a synthetic stereo view. White dots denote divide between drainages trending north and eastward from those trending south and eastward (see discussion of geomorphology). 
show the dark surface strewn with what may be rounded water-ice cobbles (Tomasko et al., 2005). These range from 5 to $15 \mathrm{~cm}$ in size and place constraints on the ability of the methane flows to transport material (Tomasko et al., 2005). The lower right panel in Fig. 8 covers the area mapped stereoscopically as Region 2 . As noted the error in the relief in Figs. 6 and 7 may be as much $30-50 \mathrm{~m}$; but it is clear that the bright units protrude as ridges above the dark plain.

Fig. 9 is an interpretive map of inferred flow directions and structural lineaments that appear to partly control the patterns of both the drainage systems as well as parts of the "coastline" between bright highlands and the lower dark plains. The flow patterns are interpreted from a composite of information (1) taken directly from the DTMs, (2) mapped from the dark channel floors that stand out against the bright highland material, (3) mapped from higher resolution images in which erosive channels can

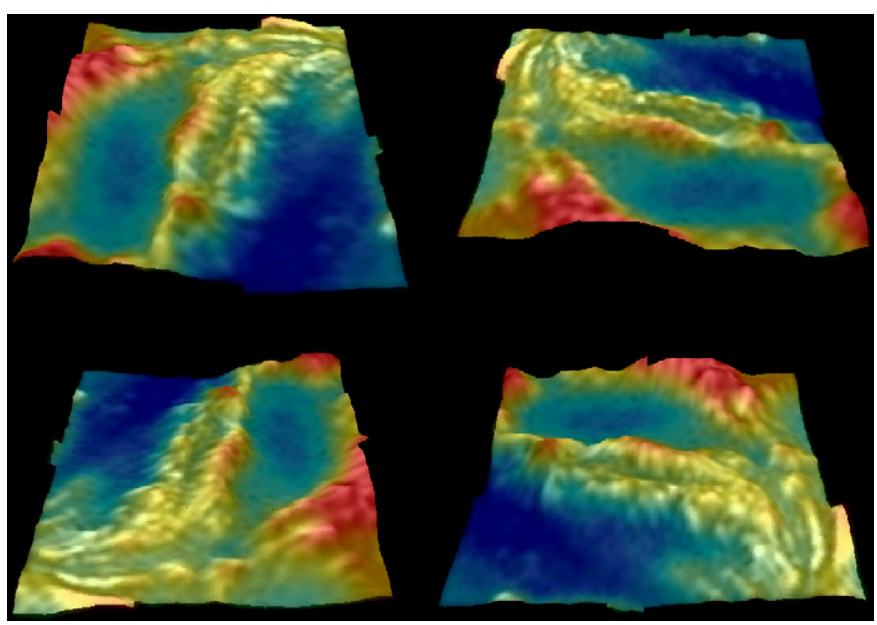

Fig. 6. Four perspective views of the DTM derived from a single stereo pair for Region 2 (upper left: $\mathrm{N}$-looking, upper right: E-looking, lower left: S-looking, lower right: W-looking). The MRI image was orthorectified, mosaicked, and color-coded in elevation (blue-to-red $\sim 250 \mathrm{~m}$ ) and then rendered into these $3-\mathrm{D}$ views. There is no vertical exaggeration. clearly be seen in the dark plain (cf. Fig. 8 lower left), and (4) inferred from patterns of bright markings in the dark plains (e.g. along-shore shoals and sandbar-like features, patterns that taper downstream). It appears that although there is clearly flow through and from the highlands down into the lower darker plains, major flow across the plain is parallel to the "coastline" with major flows from west to east across the region (but locally range from northeasterly to southwesterly). This suggests major sources of liquid methane/ethane in some region(s) to the west. It is interesting to speculate whether there is liquid exposed at the surface in those areas; the Huygens probe landed on a dry plain but liquid methane appeared to be present just below the surface (Niemann et al., 2005; Lorenz et al., 2006a) (Fig. 9).

Perron et al. (2006) modeled methane precipitation rates required to erode the dendritic valleys in the highlands to the north of the HLS (e.g. Region 1). They note that modeled precipitation rates are highly dependent on the size of the material entrained in transport. They used size ranges taken from the landing site images of $1-10 \mathrm{~cm}$ and infer precipitation rates of $0.5-15 \mathrm{~mm} \mathrm{~h}^{-1}$. However the cobbles seen at the HLS may not be at all representative of the grain size of the material transported in the dendritic highland channels to the north. These cobbles $(5-15 \mathrm{~cm}$ from Tomasko et al., 2005) may only pertain to the floods that we infer have scoured the dark HLS plain flowing from west to east.

\section{Summary}

The Huygens landing site is in a region of bright and dark units that is free of the pervasive dune fields found elsewhere, the nearest being $\sim 30 \mathrm{~km}$ north of the landing site. The geomorphology of the landing site region is that of bright rugged higher terrain and lower water-ice rich dark plain, in which fluvial and pluvial erosional and depositional processes, often reflecting tectonic control,

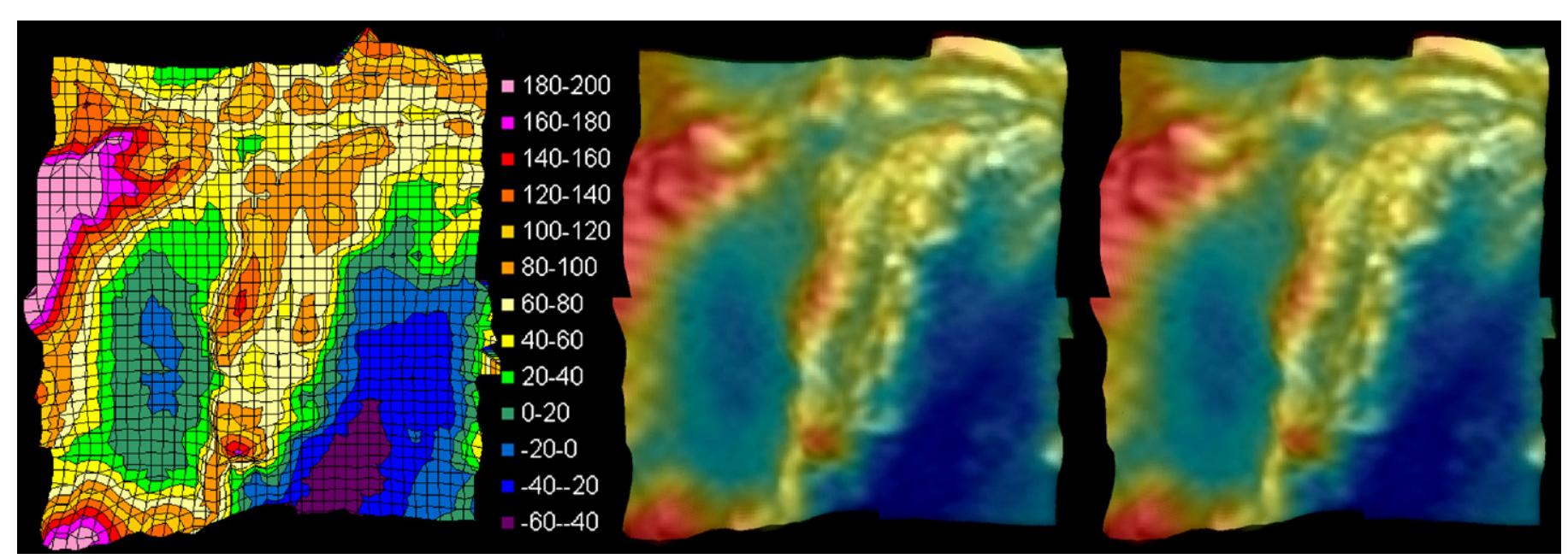

Fig. 7. Vertical views of the DTM for Region 2. Left: Elevations are color-sliced and provided with a scale (units are in meters; grid spacing is $50 \mathrm{~m}$ ). Right pair: The elevation-color-coded orthorectified MRI image used in Fig. 6 is rendered as a synthetic stereo view. 

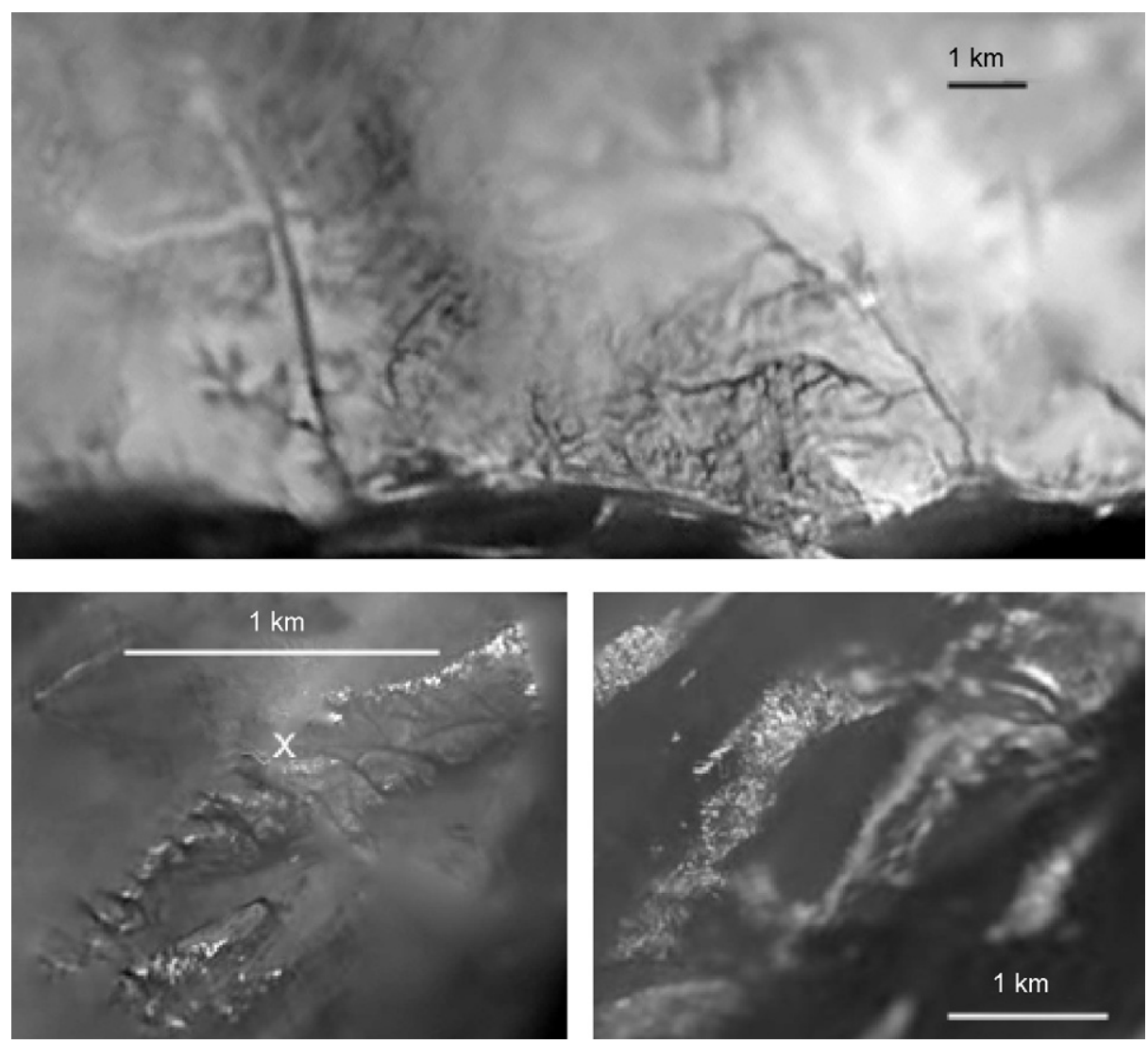

Fig. 8. Patterns of integrated drainage, flow, and erosional scour in the Huygens landing site region. Upper: two styles of drainage networks in the bright region 5-10 km north of the Huygens landing site $(16 \mathrm{~m} /$ pixel). Lower left: high-resolution $(2 \mathrm{~m} / \mathrm{pixel})$ view of the erosional channels around the Huygens landing site (marked with white $\mathrm{x})$. Lower right: medium-resolution view $(8 \mathrm{~m} /$ pixel) of bright ridges standing above the dark plain evidently carved by surface flow based on the stereo model in Region 2 (center $4 \mathrm{~km}$ ESE of the landing site). Mosaics are from Karkoschka, 2006.

and are the major ongoing processes in the roughly 100 square kilometers around the landing site. The digital elevation models constructed from these images show rugged topography in places approaching the angleof-repose, mixed with flat plains. Brighter highland regions display two styles of drainage patterns: short, stubby loworder drainage channels (second or third order) suggestive of methane spring-sapping and in rough topography and complex branching drainage systems with high-order (up to fourth order) suggestive of methane/ethane rainfall. The topographic data show that the slopes in bright terrain being dissected by the high-order drainage channels are extremely rugged; slopes of order of $30^{\circ}$ appear common. These systems drain into adjacent relatively flat, dark lowland terrains. The model of Soderblom et al. (this issue) suggests the immediate region of the HLS to consist of a dark, dirty water-ice substrate that is mantled with bright deposits in the highlands regions a few kilometers to the north. If that model is valid then the dark channels of the highlands to the north and the plains of the HLS itself represent the exposed dark water-ice-rich substrate.

In addition to flow from the highlands drainages, the lowland area shows evidence for additional flow parallel to the highland-lowland boundary leaving bright outliers resembling terrestrial sandbars. This implies major W-to-E

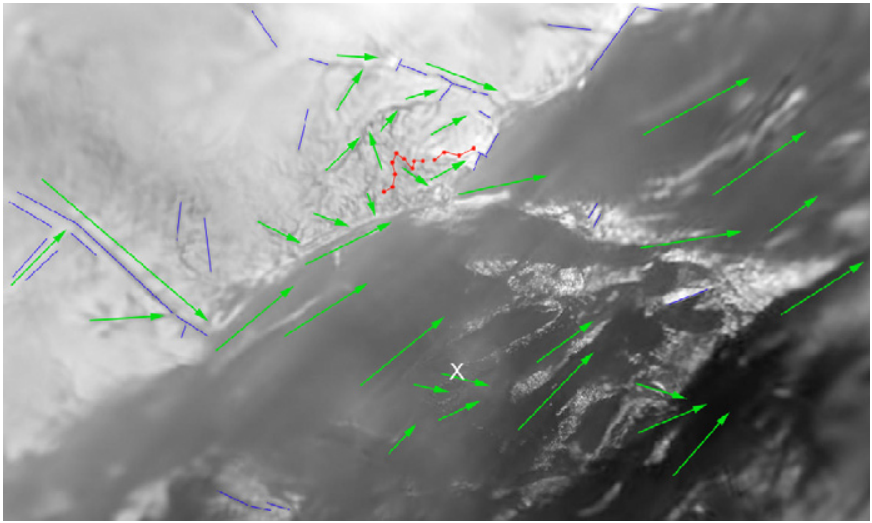

Fig. 9. Inferred tectonic and fluid-flow patterns: tectonic patterns are blue; drainage divide is red; flow directions are shown as green arrows; and the Huygens landing site marked by the white " $\mathrm{x}$ ". The area covered is $\sim 18.3 \times 10.9 \mathrm{~km}\left(\sim 10.2-10.5^{\circ} \mathrm{S}, 192.2-192.6^{\circ} \mathrm{W}\right)$; the map projection is simple cylindrical (16 m/pixel). Base mosaic from Karkoschka (2006).

floods across the plains with flow parallel to the highlandlowland boundary. Consistent with this hypothesis, images taken after landing on the surface show abundant $5-15 \mathrm{~cm}$ sized rounded and smooth cobbles strewn about an apparent flood plain. A stereo model for part of the dark 
plains region east of the landing site shows surface scour flowing to the east leaving a laced pattern of bright ridges that are on order of $100 \mathrm{~m}$ high. Tectonic patterns are also evident in controlling (1) the rectilinear, low-order, stubby drainages and (2) the numerous straight and angular margins along the "coastline" separating highland-lowland boundary. Because the features appear to be fresh and hence quite young, they suggest that occasionally the nowsubsaturated equatorial atmosphere becomes moistened with enough methane to create violent rainfall and hence the erosion seen in the DISR images.

\section{Acknowledgments}

This work was funded by the Cassini Project conducted for NASA by the Jet Propulsion Laboratory, California Institute of Technology. The authors wish to thank Ken Herkenhoff, Ken Tanaka, and two unidentified reviewers for insightful and constructive criticism.

\section{References}

Archinal, B.A., Tomasko, M.G., Rizk, B., Soderblom, L.A., Kirk, R.L., Howington-Kraus, E., Cook, D.A., Becker, T.L., Rosiek, M.R., Galuszka, D., Redding, B.L., Hare, T.L., DISR Science Team, 2006. Topographic mapping of the Huygens landing site on Titan: new results and error analyses. Publication of the 37th Annual Lunar and Planetary Science Conference, League City, Texas, March 13-17, 2006, Abstract No.2089.

Barnes, J. W., Brown, R. H., Soderblom, L., Buratti, B. J., Sotin, C., Rodriguez, S., Le Mouèlic, S., Baines, K. H., Clark, R., Nicholson, P., 2007. Global-scale surface spectral variations on Titan seen from Cassini/VIMS. Icarus 186, 242-258.

Collins, Geoffrey C., 2005. Relative rates of fluvial bedrock incision on Titan and Earth. Geophys. Res. Let. 32 (22, L22202), 1-4.

Coustenis, A., Lellouch, E., Maillard, J.P., McKay, C.P., 1995. Titan's surface: composition and variability from the near-infrared albedo. Icarus $118,87-104$.

Coustenis, A., Hirtzig, M., Gendron, E., Drossart, P., Lai, O., Combes, M., Negrão, A., 2005. Maps of Titan's surface from 1 to $2.5 \mu \mathrm{m}$. Icarus 177 (1), 89-105.

de Pater, I., Ádámkovics, M., Bouchez, A. H., Brown, M. E., Gibbard, S. G., Marchis, F., Roe, H. G., Schaller, E. L., Young, E., 2006. Titan imagery with Keck adaptive optics during and after probe entry. J. Geophys. Res. 111(E7, E07S05) 1-16.

Grieger, B., Doose, L., Karkoschka, E., Keller, H.U., Kramm, R., Skorov, Y., Tomasko, M.G., 2006. The Disr team topographic shading in Huygens/DISR images of Titan's surface. In: 36th COSPAR Scientific Assembly, Beijing, China, p. 2892.

Griffith, C.A., Owen, T., Geballe, T.R., Rayner, J., Rannou, P., 2003. Evidence for the exposure of water ice on Titan's surface. Science 300, 628-630.

Hirtzig, M., Coustenis, A., Gendron, E., Drossart, P., Hartung, M., Negrão, A., Rannou, P., Combes, M., 2007. Titan: atmospheric and surface features as observed with Nasmyth Adaptive Optics System Near-Infrared Imager and Spectrograph at the time of the Huygens mission. J. Geophys. Res. 112 (E2, E02S91), 1-12.

Karkoschka, E., 2006. 〈http://webgis.wr.usgs.gov/pigwad/down/titan_dl. htm. $>$.

Lewis, J.S., 1971. Satellites of the outer planets: their physical and chemical nature. Icarus $15,174-185$.

Lopes, R.M.C., Mitchell, K.L., Stofan, E.R., Lunine, J.I., Lorenz, R., Paganelli, F., Kirk, R.L., Wood, C.A., Wall, S.D., Robshaw, L.E., Fortes, A.D., Neish, C.D., Radebaugh, J., Reffet, E., Ostro,
S.J., Elachi, C., Allison, M.D., Anderson, Y., Boehmer, R., Boubin, G., Callahan, P., Encrenaz, P., Flamini, E., Francescetti, G., Gim, Y., Hamilton, G., Hensley, S., Janssen, M.A., Johnson, W.T.K., Kelleher, K., Muhleman, D.O., Ori, G., Orosei, R., Picardi, G., Posa, F., Roth, L.E., Seu, R., Shaffer, S., Soderblom, L.A., Stiles, B., Vetrella, S., West, R.D., Wye, L., Zebker, H.A., 2007. Cryovolcanic features on Titan's surface as revealed by the Cassini Titan Radar Mapper. Icarus 186, 395-412.

Lorenz, R.D., Niemann, H.B., Harpold, D.N., Way, S.H., Zarnecki, J.C., 2006a. Titan's damp ground: constraints on Titan surface thermal properties from the temperature evolution of the Huygens GCMS inlet. Meteoritics Planet. Sci. 41, 1705-1714.

Lorenz, R.D., Wall, S., Radebaugh, J., Boubin, G., Reffet, E., Janssen, M., Stofan, E., Lopes, R., Kirk, R., Elachi, C., Lunine, J., Mitchell, K., Paganelli, F., Soderblom, L., Wood, C., Wye, L., Zebker, H., Anderson, Y., Ostro, S., Allison, M., Boehmer, R., Callahan, P., Encrenaz, P., Ori, G.G., Francescetti, G., Gim, Y., Hamilton, G., Hensley, S., Johnson, W., Kelleher, K., Muhleman, D., Picardi, G., Posa, F., Roth, L., Seu, R., Shaffer, S., Stiles, B., Vetrella, S., Flamini, E., West, R., 2006b. The sand seas of Titan: Cassini RADAR observations of longitudinal dunes. Science 312 (5774), 724-727.

Lunine, J.I., Elachi, C., Wall, S. D., Allison, M.D., Anderson, Y., Boehmer, R., Callahan, P., Encrenaz, P., Flamini, E., Franceschetti, G., Gim, Y., Hamilton, G., Hensley, S., Janssen, M.A., Johnson, W.T.K., Kelleher, K., Kirk, R.L., Lopes, R.M., Lorenz, R., Muhleman, D.O., Orosei1, R., Ostro, S.J., Paganelli, F., Paillou, P., Picardi, G., Posa, F., Radebaugh, J., Roth, L.E., Seu, R., Shaffer, S., Soderblom, L.A., Stiles, B., Stofan, E.R., Vetrella, S., West, R., Wood, C.A., Wye, L., Zebker, H., Albertil, G., Karkoschka, E., Rizk, B., McFarlane, E., See, C., Kazeminejad, B., Cassini RADAR's third and fourth looks at Titan, Icarus, submitted for publication.

McCord, T.B., Hansen, G.B., Buratti, B.J., Clark, R.N., Cruikshank, D.P., D’Aversa, E., Griffith, C.A., Baines, E.K.H., Brown, R.H., Dalle Ore, C.M., Filacchione, G., Formisano, V., Hibbitts, C.A., Jaumann, R., Lunine, J.I., Nelson, R.M., Sotin, C., the Cassini VIMS Team, 2006. Composition of Titan's surface from Cassini VIMS. Planet. Space Sci. 54 (15), 1524-1539.

Negrão, A., Coustenis, A., Lellouch, E., Maillard, J.-P., Rannou, P., Schmitt, B., McKay, C.P., Boudon, V., 2006. Titan's surface albedo variations over a Titan season from near-infrared CFHT/FTS spectra. Planet. Space Sci. 54, 1225-1246.

Negrão, A., Hirtzig, M., Coustenis, A., Gendron, E., Drossart, P., Rannou, P., Combes, M., Boudon, V., 2007. The 2- $\mu$ m spectroscopy of Huygens probe landing site on Titan with very large Telescope/ Nasmyth Adaptive Optics System Near-Infrared Imager and Spectrograph. J. Geophys. Res. 112 (E2, E02S92), 1-14.

Niemann, H.B., Atreya, S.K., Bauer, S.J., Carignan, G.R., Demick, J.E., Frost, R.L., Gautier, D., Haberman, J.A., Harpold, D.N., Hunten, D.M., Israel, G., Lunine, J.I., Kasprzak, W.T., Owen, T.C., Paulkovich, M., Raulin, F., Raaen, E., Way, S.H., 2005. The composition of Titan's atmosphere from the GCMS on the Huygens probe, and implications for the origin of nitrogen and methane. Nature 438, 779-784.

Perron, J.T., Lamb, M.P., Koven, C.D., Fung, I.Y., Yager, E., Ádámkovics, M., 2006. Valley formation and methane precipitation rates on Titan. J. Geophys. Res. 111 (E11, E11001), 1-14.

Rodriguez, S., Le Mouélic, S., Sotin, C., Clénet, H., Clark, R.N., Buratti, B., Brown, R.H., McCord, T.B., Nicholson, D., Baines, K.H., the VIMS Science Team, 2006. Cassini/VIMS hyperspectral observations of the HUYGENS landing site on Titan. Planet. Space Sci. 54, 1510-1523.

Soderblom, L. A., DISR, Cassini-Huygens, RADAR, VIMS Teams, this issue. Titan's Surface Properties: Correlations Among DISR, RADAR and VIMS Observations. American Astronomical Society, DPS Meeting \#38, \#52.08.

Stevenson, D.J., 1992. The interior of Titan. In: Proceedings of the Symposium on Titan, ESA SP-338. ESA, Noordwijk, The Netherlands, pp. 29-33. 
Tomasko, M.G., Buchhauser, D., Bushroe, M., Dafoe, L.E., Doose, L.R., Eibl, A., Fellows, C., McFarlane, E.M., Prout, G.M., Pringle, M.J., Rizk, B., See, C., Smith, P.H., Tsetsenekos, K., 2002. The Descent Imager/Spectral Radiometer (DISR) experiment on the Huygens entry probe of Titan. Space Sci. Rev. 104 (1), 469-551.

Tomasko, M.G., Archinal, B., Becker, T., Bézard, B., Bushroe, M., Combes, M., Cook, D., Coustenis, A., de Bergh, C., Dafoe, L.E., Doose, L., Douté, S., Eibl, A., Engel, S., Gliem, F., Grieger, B., Holso,
K., Howington-Kraus, E., Karkoschka, E., Keller, H.U., Kirk, R., Kramm, R., Küppers, M., Lanagan, P., Lellouch, E., Lemmon, M., Lunine, J., McFarlane, E., Moores, J., Prout, G.M., Rizk, B., Rosiek, M., Rueffer, P., Schröder, S.E., Schmitt, B., See, C., Smith, P., Soderblom, L., Thomas, N., West, R., 2005. Rain, winds and haze during the Huygens probe's descent to Titan's surface. Nature 438 (7069), 765-778. 